\title{
Influence of Peer Learning on Students' Academic Performance (The Case of 2010 E.C for the Course Chemical Thermodynamics at Assosa University)
}

\author{
Asmamaw Taye Guyaho \\ Department of Chemistry, College of Natural and Computational Science, Assosa University, Assosa, Ethiopia \\ Email address: \\ asmamawtaye@gmail.com

\section{To cite this article:} \\ Asmamaw Taye Guyaho. Influence of Peer Learning on Students' Academic Performance (The Case of 2010 E.C for the Course Chemical \\ Thermodynamics at Assosa University). International Journal of Education, Culture and Society. Vol. 5, No. 6, 2020, pp. 115-119. \\ doi: $10.11648 /$ j.ijecs.20200506.11
}

Received: September 28, 2020; Accepted: October 27, 2020; Published: November 11, 2020

\begin{abstract}
Peer teaching is a suite of practices in which peers instruct each other in a purpose driven, meaning full interaction. Many universities are facing challenges due to the increasing number of young people attending higher education. Learning is enhanced when it is more like a team effort than a solo race. This study explores how peer learning influences the academic performance of students and it also resolves the negative attitude of teachers and students on the active teaching learning process. It increases student's social interaction as well as subject matter knowledge. The study was conducted in Assosa university Chemistry department second year students on chemical thermodynamics course. The data was analyzed by using percentage and mean using tables. The tolls of data collection were mainly questionnaires, interview and observations. As peer learning is implemented frequently, the score of the student was increased. Students will learn from one another because in their discussion of the content, cognitive conflicts will arise, inadequate reasoning will be exposed, and higherquality understanding will emerge. Finally, this finding recommends that in most chemistry courses, a team work is important to increase the academic performance of students and it could be applicable.
\end{abstract}

Keywords: Peer Learning, Academic Performance, Students, Chemistry, Interaction

\section{Background of the Study}

\subsection{Introduction}

Managing different students in a way that supports their academic performance is a huge challenge, which is magnified in large compulsory. One way to bridge the distance among new students in a university is to develop the habit of peer learning among them. Peer learning is a pedagogical technique that is characterized by the attainment of knowledge and skill by peers who are at a similar level of proficiency. It is defined as the formation of "small, structured and heterogeneous groups" to cover the content. It is supposed to be a mutually beneficial experience [1].

Many universities are facing challenges due to the increasing number of young people attending higher education. The sheer number of students raises the question of how to organize teaching-learning activities that allow the students to become active learners and engaged participants in academic discussions within their disciplines rather than passive spectators [13]. Learning is enhanced when it is more like a team effort than a solo race [2]. peer learning is a philosophy that fits in today's globalized world where people are working together, building together, changing together, improving together [5].

Peer teaching is a suite of practices in which peers instruct each other in a purpose-driven, meaningful interaction. Many programs feature older, more experienced peers, or those with greater mastery in a subject area teaching younger, lessexperienced peers or those who are yet to master the skills and content of the subject area.

Students are required to be able to think creatively, solve problems, and make decisions as a team [2]. In cooperative classroom, different people are learning to work together towards a common goal which will provide an opportunity to become better citizens of the world. It provides the 
mechanism for students to interact positively with people who think differently, not only locally, but also worldwide. In today's world, our graduates need to have more than the body of knowledge and skills of the specific discipline. Educational stakeholders also now expect them to have generic personal attributes that make them a valuable and worthy employee. Therefore, the learning goals should be characterized by the high quality of their skills, knowledge and attitudes relevant for employment, particularly in the knowledge-based services and professions.

To be a competent and globalized person, graduates must be able to work in team where good interpersonal skills and the capacity to work both autonomously and collaboratively as a professional are required. A apart from some professional practice areas, little of the knowledge is applied in job settings [3]. Thus, employers are more concerned about a variety of personal and interpersonal skills and abilities than they are job-related knowledge.

This study explores how peer learning influences the academic performance of students. Dependent variables including enhancement and enrichment in students ' learning experience, positive attitude towards the subject matter, social interaction skills development and communication skills improvement are all-important components to further understanding the effectiveness of peer learning in the university chemistry classroom. This paper has six chapters; such as: introduction, literature review, methodology of the study, result and discussion, conclusion and recommendation and references.

\subsection{Statement of the Problem}

In most cases, the university instructors are implementing lecture method in preference to other teaching methods. But this does not promote peer learning habit in the students. So as a result of this, the students' academic performance is low with respect to educational outcomes and the set standard. Therefore, the main impression that makes us to select this topic is to enhance the habit of peer learning to improve students' academic achievement. Finally this research work is expected to answer the following questions.

What is the level of implementation of peer learning habit in science courses in Assosa University?

What is the effect of peer learning habit on students' performance?

What are the factors that affect peer learning habit among the instructors and pupils?

\subsection{Objectives of the Study}

\subsubsection{General Objective}

To assess the influence of peer learning habit on students' performance.

\subsubsection{Specific Objective}

1. To promote active learning experiences in students in the classroom

2. To compare results of students who practice peer learning and who did not practice peer learning.
3. To create positive attitude for the students towards peer learning

\subsection{Significance of the Study}

This study conveys information about the importance of peer learning in delivering course for students by their instructors. So that, it creates opportunity for other researchers to look curiously about the effect of peer learning towards students' academic achievements. Moreover, it resolves the negative attitude of teachers and students on the active teaching learning process. Finally, peer learning is expected to increase student's social interaction as well as subject matter knowledge.

\section{Review Literature}

"Peer learning is an educational practice in which students interact with other students to attain educational goals."[4] In this context, it can be compared to the practices that go by the name cooperative learning. However, other contemporary views on peer learning relax the constraints, and position "peer-to-peer learning" as a mode of "learning for everyone, by everyone, about almost anything."[9] Whether it takes place in a formal or informal learning context, in small groups or online, peer learning manifests aspects of selforganization that are mostly absent from pedagogical models of teaching and learning.

Peer Instruction engages students during class through activities that require each student to apply the core concepts being presented, and then to explain those concepts to their fellow students [14]. A key challenge when aiming at peer learning is that peers are not domain experts, as opposed to teachers, which means that the accuracy of peer feedback can vary greatly. Feedback from peers may be partially correct, fully incorrect or misleading [15].

Peer effects are not "one-size-fits-all," but rather exhibit striking differences across students of different abilities and across different segments of the peer ability distribution. For example, the weakest students appear to experience the biggest positive impact from having higher quality peers [16]

Many students have wished to see their teachers and fellow students and talk to them, not just write everything down. This can be realized in several ways. Some assignments can be created as group assignments, where the participants can see and talk to each other through Skype or arrange to meet in person if they get to participate with one or two students who live nearby. These assignments could be created as two-step assignments to promote feedback through dialogue. Another way is to plan a couple of Skype meetings (audio) where the students can ask questions and bring up subjects that they find hard to write about. [15]

A number of manifestations of peer teaching, as well as the range of labels applied to these practices, including "peer tutoring, cross-age tutoring, peer teaching, peer education, partner learning, peer learning, child-teach-child, learningthrough-teaching were identified [6].

The list of reported benefits of peer teaching include im- 
proving competence in the subject area, easing students into university life, the development of autonomous learning skills, "developing networking opportunities; building confidence and self-esteem; enhancing team-working skills, and developing leadership skills" [8]; and positive attitudes toward school and subject area [7].

\section{Methodology}

\subsection{Sampling Design and Techniques}

Multi stage sampling technique was used for the study. In the first stage College of natural and computational sciences was purposively selected, in the second stage department of chemistry was also selected purposively. Finally, all second year students of chemistry were chosen for the purpose of the study.

\subsection{Data Type and Sources}

Both primary and secondary data were collected. Primary data was collected from the instructors and second year students of chemistry department. The secondary data was collected from relevant sources such as books, master sheets from the department, internet and journal articles.

\subsection{Data Collection Methods}

Questionnaires and observation were used as data collection tool. The questionnaire was distributed to sample students to gather the relevant information. Three consecutive exams were given for the sample students before and after practicing peer learning. The secondary data was collected from different documents through reviewing secondary sources.

\subsection{Methods of Data Analysis}

The target groups in this study were the second year chemistry students. Data was analyzed using descriptive statistics such as, mean and percentage. The results obtained after analysis was discussed by using tables, charts and in statements.

\section{Results and Discussion}

In order to assess the implementation level, pre knowledge and post knowledge of students towards peer learning method application, both close ended and open ended questionnaires were developed and distributed for the targeted students. The results obtained was analyzed and summarized as follows.

The number of respondents was male $17(48.57 \%)$ and female $18(51.43 \%)$. for the open ended questions about 25 $(71.43 \%)$ of students knows about peer learning but 10 (28.57\%) of the respondents are new for the peer learning method. Most of the respondents around 27 (77.14\%) are interested in peer learning method. But there were few students who are not interested on it. Around 23 (65.71\%) of the respondent says that, they have practiced peer learning in the class. The result again reveals that around $29(82.86 \%)$ believes that peer learning will improve their academic performance. But the rest respondents (17.14\%) did not believe it to improve their performance. Most of the students $26(74.29 \%)$ agreed up on the absence of facilities in the class to implement peer learning method. Almost all respondents (31) said that they meet for peer learning once a week. According to $57 \%$ of the respondents, the group leader makes them to involve actively in peer learning. 15 (42.9\%) of the respondents said that, the instructors allow them to learn in peer. But the remaining respondents 20 (57.1\%) reported that the instructors did not support them in peer learning.

For the open ended questions of this part, according to some respondents, the instructors promote peer learning habit of students by giving home work, class activity, assignment, and group discussion and home take exams. Most respondents define peer learning as a means of sharing ideas, experiences and knowledge among the individuals. But there were some respondents who did not explain it well or their ideas were not clear for analysis.

Since this research is action research, the researchers were tried to implement peer learning method and asses the students. As a result, after treating the students by using peer learning method again open ended questions were developed and distributed for those targeted students in order to check the changes with regard to this method. Accordingly, most respondents said that, peer learning method brings change in the score of them. The result reveals that, they prefer peer learning as best way to share experiences and knowledge. The targeted group agreed that, Peer learning brings behavioral change among the students special by increasing the score of the students. All students agreed that, Peer learning brings attitude change towards the students because it was best way for increasing academic achievement.

After collecting information with regard to the level of implementation of peer learning from the selected students as a need assessment, students was thought by different stages of peer learning the score of the students were analyzed.

The table below here describes the score of 2011 E. C second year second semester chemistry students' chemical thermodynamic course. For the sake of security, students have given code number from 101 up to 135 rather than writing their name. The test was given out of $25 \%$ and converted in to $100 \%$ for the same students three times in different contents. for the first time, the students was thought by using other teaching methods which is quite different from peer learning and the score of the student was registered in table below. Secondly, these selected students were thought by using peer teaching method and the score was registered on the other column. Finally, in order to check the influence of peer learning on the academic performance of these students, peer learning method was used again for the second time in different content and after assessment the score was registered on other different column. Moreover, the mean score of students were analyzed and compared in each 
stage of application of peer learning method.

Table 1. The score/result of students in each stage of application of peer learning method.

\begin{tabular}{|c|c|c|c|c|}
\hline No & Code number of students & $\begin{array}{l}\text { Exam score of students } \\
\text { before using peer learning } \\
(100 \%)\end{array}$ & $\begin{array}{l}\text { Exam score of students } \\
\text { after using peer learning at } \\
\mathbf{1}^{\text {st }} \text { stage }(100 \%)\end{array}$ & $\begin{array}{l}\text { Exam score of students } \\
\text { after using peer learning at } \\
\mathbf{2}^{\text {nd }} \text { stage }(100 \%)\end{array}$ \\
\hline 1 & 101 & 74 & 72.5 & 82 \\
\hline 2 & 102 & 60.25 & 61 & 64 \\
\hline 3 & 103 & 63 & 69 & 72 \\
\hline 4 & 104 & 38 & 43 & 49 \\
\hline 5 & 105 & 71.5 & 73 & 79 \\
\hline 6 & 106 & 63 & 67 & 68 \\
\hline 7 & 107 & 59 & 52 & 60 \\
\hline 8 & 108 & 82 & 82 & 85 \\
\hline 9 & 109 & 55 & 59 & 61 \\
\hline 10 & 110 & 78 & 84 & 80 \\
\hline 11 & 111 & 78 & 77 & 81 \\
\hline 12 & 112 & 65.75 & 70 & 72 \\
\hline 13 & 113 & 48 & 52 & 51 \\
\hline 14 & 114 & 67 & 78 & 75 \\
\hline 15 & 115 & 47 & 56.2 & 58 \\
\hline 16 & 116 & 60 & 61 & 59 \\
\hline 17 & 117 & 75 & 78 & 79 \\
\hline 18 & 118 & 56 & 58 & 59 \\
\hline 19 & 119 & 64 & 70 & 72 \\
\hline 20 & 120 & 68.7 & 69 & 75 \\
\hline 21 & 121 & 61 & 60 & 67 \\
\hline 22 & 122 & 66 & 70 & 71 \\
\hline 23 & 123 & 66 & 71 & 81 \\
\hline 24 & 124 & 84 & 85 & 87 \\
\hline 25 & 125 & 62 & 64 & 60 \\
\hline 26 & 126 & 39 & 43 & 49 \\
\hline 27 & 127 & 60 & 61 & 65 \\
\hline 28 & 128 & 64.5 & 66 & 67 \\
\hline 29 & 129 & 66.25 & 67 & 68 \\
\hline 30 & 130 & 63.4 & 65.5 & 68 \\
\hline 31 & 131 & 72 & 74.5 & 76 \\
\hline 32 & 132 & 65 & 66 & 68 \\
\hline 33 & 133 & 47.75 & 50 & 56 \\
\hline 34 & 134 & 49 & 56 & 55 \\
\hline 35 & 135 & 51 & 52 & 56 \\
\hline \multicolumn{2}{|c|}{ Mean score } & 62.57 & 65.22 & 67.80 \\
\hline \multicolumn{2}{|c|}{ Highest score } & 84 & 85 & 87 \\
\hline \multicolumn{2}{|c|}{ Lowest score } & 38 & 43 & 49 \\
\hline \multicolumn{2}{|c|}{$\%$ of students scoring $<50 \%$} & 17.14 & 5.71 & 5.71 \\
\hline \multicolumn{2}{|c|}{$\%$ of students scoring [50_70] } & 60 & 60 & 51.43 \\
\hline \multicolumn{2}{|c|}{$\%$ of students scoring $>70 \%$} & 22.86 & 34.29 & 42.86 \\
\hline \multicolumn{2}{|c|}{$\begin{array}{l}\% \text { of students whose score progressively increase as } \\
\text { peer learning method is implemented. }\end{array}$} & 74.29 & & \\
\hline \multicolumn{2}{|c|}{$\begin{array}{l}\% \text { of students whose score irregularly increase or } \\
\text { decrease as peer learning method is implemented. }\end{array}$} & 25.71 & & \\
\hline
\end{tabular}

The result from the above table reveals that, the mean score of the students increases slightly from 62.57 to 67.80 as the rate of utilization repeatability of peer learning proceeds. As indicated from the above table the maximum and minimum score of students was improved when they are treated in peer. The number of students scoring less than $50 \%$ before using peer learning method, after using peer learning method at $1^{\text {st }}$ and repeated again for the second time in different content is $17.14 \%, 5.71 \%$ and $5.71 \%$ respectively. This result shows that as peer learning method was used repeatedly, it influences the score of students positively. The $\%$ of students scoring [50_70] was slightly decreasing from $60 \%$ to $51.43 \%$. This is due to the medium scorer students were being shifted to the higher scorer i.e. they score greater than $70 \%$.
The number of Students scoring $>70 \%$ was radically increased. This shows that peer learning method is the best for those medium class students rather than the higher achievers. The score of lower achiever students were highly increased when peer learning was applied. As seen from the table above again, when peer learning is implemented more and more the score of $74.29 \%$ of students were significantly increased. But there were some students (25.71\%) whose score was irregularly increasing and decreasing when peer learning method was applied. This indicates that there is some learning method preference for each individual during teaching learning process.

The above finding was in agreement with [2], which says 
that, the active exchange of ideas within small groups not only increases interest among the participants but also promotes critical thinking and the effectiveness of peer learning as it relates to learning outcomes at the university level. Interaction among students on learning tasks will lead in itself to improved student achievement. As supported by [10] Students will learn from one another because in their discussion of the content, cognitive conflicts will arise, inadequate reasoning will be exposed, and higher-quality understanding will emerge.

Information is better understood, processed and recalled, if students have an opportunity to elaborate on that information... through discussing the subject matter with other students, teaching peers what they have learned themselves, exchanging views about how the information applies to the problem they are seeking to solve [11].

Group learning, as opposed to didactic teaching, appears to empower students to learn and with this, to generate within students a responsibility for their own learning [12]. They also propose that peer support, and providing and receiving help from each other, seems to lead to increased engagement in the task and perseverance. Peer norms also appear to encourage individual effort.

\section{Conclusion and Recommendation}

\subsection{Conclusion}

This study explores how peer learning influences the academic performance of students. Most of the respondents had awareness, interest and practice on peer learning method. Most students believe that this method can improve the students' academic performance. According to most respondents, they meet once a week for peer learning; the group leaders and the instructors makes them to participate actively. But there were lack of sufficient facilities to implement peer learning in the class. There were some students who were new for peer learning.

The score of students was compared with out implementing peer learning method, by applying peer learning method and by implementing it frequently for repeated time. Accordingly the score increases as the frequency of implementation of peer learning method increases. Generally peer learning method increases the academic performance, the positive social interaction and experience sharing habit of the students.

\subsection{Recommendation}

Peer learning method improves the academic performance of the students. In addition to implementing other methods, teachers were recommended to use this method. It is free for other scholars to conduct the same research on different courses and different teaching/learning methods.

\section{References}

[1] Topping, K. J. (2005). Trends in Peer Learning, 25 (6), 631645. http://doi.org/10.1080/01443410500345172

[2] Gokhale, A. A. (1995). Collaborative learning enhances critical thinking. Journal of Technology Education 7 (1), pp. $1-8$.

[3] Harvey, L. (2003). Transitions from higher education to work. Retrieved June 28, 2006.

[4] O'Donnell, A. M.; A. King (1999). Cognitive perspectives on peer learning. Lawrence Erlbaum. ISBN 0805824480.

[5] Wiersema, N. (2000). How does collaborative learning actually work in a classroom and how dostudents react to it? A brief reflection. Retrieved November 28, 2005.

[6] Kalkowski, P. (2001). Peer and cross-age tutoring. Northwest Regional Educational Laboratory School Improvement Research Series.

[7] McNall, S. (1975). Peer teaching: A description and evaluation. Teaching Sociology, 2 (2), 133- 146.

[8] Mynard, J., \& Almarzouqi, I. (2006). Investigating peer tutoring. ELT Journal, 60 (1), 13-22.

[9] Jeff Brazil, May 23, 2011, P2PU: Learning for Everyone, by Everyone, about almost Anything Archived 2012-10-03 at the Wayback Machine.

[10] Slavin, R. E. (1990). Synthesis of Research on Cooperative Learning: Educational Leadership. Oxford: Oxford University Press.

[11] Bridges, E. M. \& Hallinger, P. (1998). Problem-based Learning in Medical and Managerial Education. In R. Fogarty (ed.), Problem-based Learning: A Collection of Articles. Arlington Hts, Illinois: Skylight Training and Publishing.

[12] Hertz-Lazarowitz, R., Kirkus, V. B. and Miller, N. (1992). Implications of Research for Classroom Application. In R. Hertz-Lazarowitz. and N. Miller, Interaction in Cooperative Groups: The Theoretical Anatomy of Group Learning. New York: Cambridge University Press.

[13] Bogale Gebeyehu College of Agriculture and Veterinary Medicine, Wolaita Sodo University Journal of Education and Practice Vol. 7, No. 34, 2016.

[14] Crouch, C. H.; Mazur, E. (2001). "Peer instruction: Ten years of experience and results". American Journal of Physics. 69 (9): 970-977. Bibcode: 2001AmJPh.69.970C. Cite Seer X 10.1.1.113.6060. doi: 10.1119/1.1374249.

[15] Larsson, A., Rydeman, B., \& Hedvall, P-O. (2012). Motivation, Peer Learning and Feedback in Flexible Learning. Paper presented at Improving Student Learning symposium 2012, Lund, Sweden.

[16] Burke, A. M. \& Tim, R. S. (2008) Classroom Peer Effects and Student Achievement. Journal of Economics. 